\title{
Article \\ Comparison of the Accuracy of Intraoral Scanners Based on the Type of Tooth Preparation for a Single Crown
}

\author{
Dong-Geun Lee ${ }^{1,+}$, Keunbada Son ${ }^{2,3,+}$ and Kyu-Bok Lee ${ }^{1,3, * \mathbb{D}}$ \\ 1 Department of Prosthodontics, School of Dentistry, Kyungpook National University, Daegu 41940, Korea; \\ kuminith@hanmail.net \\ 2 Department of Dental Science, Graduate School, Kyungpook National University, Daegu 41940, Korea; \\ sonkeunbada@gmail.com \\ 3 Advanced Dental Device Development Institute, Kyungpook National University, Daegu 41940, Korea \\ * Correspondence: kblee@knu.ac.kr; Tel.: +82-053-600-7674 \\ + These authors (Dong-Geun Lee and Keunbada Son) contributed equally to this work (co-first author).
}

Citation: Lee, D.-G.; Son, K.; Lee K.-B. Comparison of the Accuracy of Intraoral Scanners Based on the Type of Tooth Preparation for a Single Crown. Appl. Sci. 2021, 11, 9399. https://doi.org/10.3390/ app11209399

Academic Editor: Nicola Scotti

Received: 9 September 2021

Accepted: 7 October 2021

Published: 10 October 2021

Publisher's Note: MDPI stays neutral with regard to jurisdictional claims in published maps and institutional affiliations.

Copyright: (c) 2021 by the authors. Licensee MDPI, Basel, Switzerland. This article is an open access article distributed under the terms and conditions of the Creative Commons Attribution (CC BY) license (https:/ / creativecommons.org/licenses/by/ $4.0 /)$.

\begin{abstract}
The purpose of this study was to evaluate the accuracy of intraoral scanners in 10 abutments (five premolars and five molars) obtained in a dental clinic and to analyze the impacts of the volume and area of abutments on scanning accuracy. Abutment casts were scanned five times with a 3D contact scanner (DS10; Renishaw plc). The five scan files were lined up and then merged, and one high-resolution computer-aided design reference model (CRM) was obtained. To obtain a computeraided design test model (CTM), three types of intraoral scanners (CS3600 (Carestream Dental), i500 (Medit), and EZIS PO (DDS)) and one type of laboratory scanner (E1; 3Shape) were employed. Using 3D analysis software (Geomagic control X; 3D Systems), the accuracy of the scanners was evaluated, including optimal overlap by optimal alignment. The conformity of the overlapped data was calculated by the root mean square (RMS) value, using the 3D compare function for evaluation. As for statistical analysis, testing was conducted, using one-way and two-way ANOVA and the Tukey HSD test $(\alpha=0.05)$ for the comparison of the groups. To analyze the correlations of the volume and area of the abutments with accuracy, Pearson's correlation analysis was conducted $(\alpha=0.00625)$. Both premolar and molar abutments showed a lower RMS value on the laboratory scanner than on the intraoral scanners, and the RMS value was lower in premolars than in molars $(p<0.001)$. In the intraoral scanner group, CS3600 showed the best accuracy $(p<0.001)$. There were significant positive correlations for the volume and area of the abutments with accuracy $(p<0.001)$. The type, volume, and area of the clinically applicable abutments may affect the accuracy of intraoral scanners; however, the scanners used in the present study showed a clinically acceptable accuracy range, regardless of the type of abutment.
\end{abstract}

Keywords: intraoral scanner; accuracy; digital workflow; tooth preparation; abutment

\section{Introduction}

Breaking from the conventional dental workflow, which is dependent on the operator's experience, digital dental workflows have been made possible by the introduction of dental computer-aided design and computer-aided manufacturing (CAD/CAM) [1-3]. From a partially digital workflow that involved the process of obtaining a virtual cast through taking an oral impression, working model production, and use of a laboratory scanner [4], the use of intraoral scanners made fully digital dental workflows possible [5]. Intraoral scanners have the advantage of being able to obtain virtual casts directly from the patient's mouth without any additional work process, which is an essential element of a chairside CAD/CAM system [6,7]. Intraoral scanners can produce 3D models and scan oral and dental soft tissues quickly and easily, and can be visualized using 3D modeling, making communication between dentists and dental technicians and patients clearer [8]. If it is difficult to use an intraoral scanner in a given dental clinic due to various oral conditions, a 
digital workflow is possible through partially digital workflows (the process of obtaining a virtual cast by taking an oral impression, producing a working model, and using a laboratory scanner) [9-11].

Many previous studies have evaluated the accuracy of intraoral scanners [12-15]. To evaluate their accuracy, it is necessary to obtain a CAD test model (CTM), using an intraoral scanner, and to obtain a CAD reference model (CRM), using an industrial optical scanner or contact scanner with a high level accuracy so that it can be used as a standard [16,17]. The CRM and CTM obtained using 3D inspection software undergo an optimal overlapping process, and the accuracy is analyzed through 3D comparison [18,19]. In the analysis of the accuracy, the absolute average of the distance of all points in a cloud in the 3D modeling of the CRM and CTM is calculated, using the calculation of the root mean square (RMS) [20]. RMS values have been used for the analysis of the accuracy of scan data in many studies [21-23]. Previous studies have noted that if the scanning accuracy of virtual casts exceeds $100 \mu \mathrm{m}$, the final restoration in the maxilla and mandible may fit incorrectly, and an allowable range for a scanning accuracy of less than $100 \mu \mathrm{m}$ has been suggested based on the acceptable cement space for the fixed prostheses [24-26].

Many previous studies have reported that the greater the scanning range, the greater the error in the intraoral scanner, and that the scanning area for long-span prostheses as the complete-arch is inappropriate for fixed prostheses [27-36]. The limited space in the oral cavity, the effect of the accuracy of the intraoral scanner on the marginal and internal fit, and the effect of increasing the scan range on the accuracy of intraoral scanners are still to be investigated [30,31]. In previous studies, the accuracy of intraoral scanners was evaluated in the complete-arch [36]. However, the scanning area for the fixed prosthesis of a single crown, which is most often applied in clinical practice, is between three and five teeth, and the accuracy of the abutment is considered important [27,31]. Despite this importance, an assessment of the types of abutments used for fixed prostheses (premolar and molar) and the impacts of the volume and area of these abutments on scanning accuracy is still lacking. To aid the use of intraoral scanners in various dental clinical treatment environments, such studies need to be conducted in dental clinics.

Thus, the present study aims to analyze the accuracy of two types of abutments (premolar and molar) for fixed prostheses, using three types of intraoral scanners (CS3600, i500, and EZIS PO) and one type of laboratory scanner (3shape E1). The study also analyzes the impacts of the volume and area of the abutments on scanning accuracy. The null hypotheses in the present study are that there should be no differences in accuracy between the four types of scanners and that the volume and area of the abutments should not affect the accuracy of the scanning.

\section{Materials and Methods}

The present study was conducted as in Figure 1. To determine the sample size, a pilot experiment was conducted five times using the same experimental method as that of the present study; based on the result of the pilot experiment, it was established using power analysis software ( $\mathrm{G}^{*}$ Power v3.1.9.2, Heinrich-Heine-Universität, Düsseldorf, Germany) that there should be 15 samples ( $n=15$ per scanner; effect size $(\mathrm{f})=0.65$; actual power $=99.16 \%$; power $=99 \% ; \alpha=0.05)$.

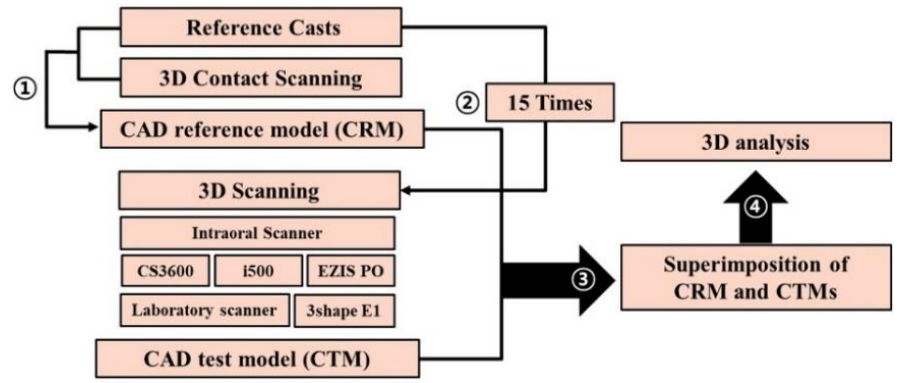

Figure 1. Experimental design. 
Since the present study obtained a conventional impression method with polyvinyl siloxane (PVS) (Aquasil Ultra; Dentsply Sirona, Bensheim, Germany) from the oral cavities of patients to produce reference casts, it was carried out after receiving the approval of the Institutional Review Board of the Kyungpook National University Dental Hospital (approval number: KNUDH-2019-02-02-02). The 10 participants were subjects who needed a single crown for ceramic prosthesis on the maxillary molar or premolar and the mandibular molar or premolar (premolar, 5; molar, 5). Of the participants, those who had poor oral health or who needed more than one crown were excluded.

Impressions of the 10 subjects were taken from their oral cavities using a PVS impression (Aquasil Ultra; Dentsply Sirona, Bensheim, Germany) and a double-arch tray (Dual Arch Impression Tray; 3M, St. Paul, MN, USA). On the basis of these impressions, a type IV dental stone (FUGIROCK; GC, Leuven, Belgium) was used to produce reference casts (premolar, 5 ; molar, 5 ). All the reference casts were produced by a skilled dental technician (K.S.).

The abutments in the reference casts were scanned using a contact 3D scanner (DS10, Renishaw plc, Gloucestershire, UK) (Figure 2). The abutments were scanned while a contact probe with a diameter of $0.5 \mathrm{~mm}$ was contacted lightly, moving upward at an interval of $200 \mu \mathrm{m}$. Each abutment was scanned three times. To produce a high-definition reference model, the scanned files were merged after optimal alignment, using reverse engineering software (Geomagic Design X, 3D Systems, Rock Hill, SC, USA), and one CRM was produced for each reference cast (Figure 2). For accurate scanning, the scan files were obtained after the calibration of the equipment by an engineer from the scanner manufacturer. With the 10 types of CRMs (premolar, 5; molar, 5) obtained, the volume and area of the upper side of the abutments were measured based on their finish lines, and the results were as follows. Volume: premolar $\left(84.2 \pm 13.6 \mathrm{~mm}^{3}\right)$, molar $\left(238.4 \pm 28.6 \mathrm{~mm}^{3}\right)$; area: premolar $\left(76.5 \pm 15.6 \mathrm{~mm}^{2}\right)$, molar $\left(165.6 \pm 18.6 \mathrm{~mm}^{2}\right)$.

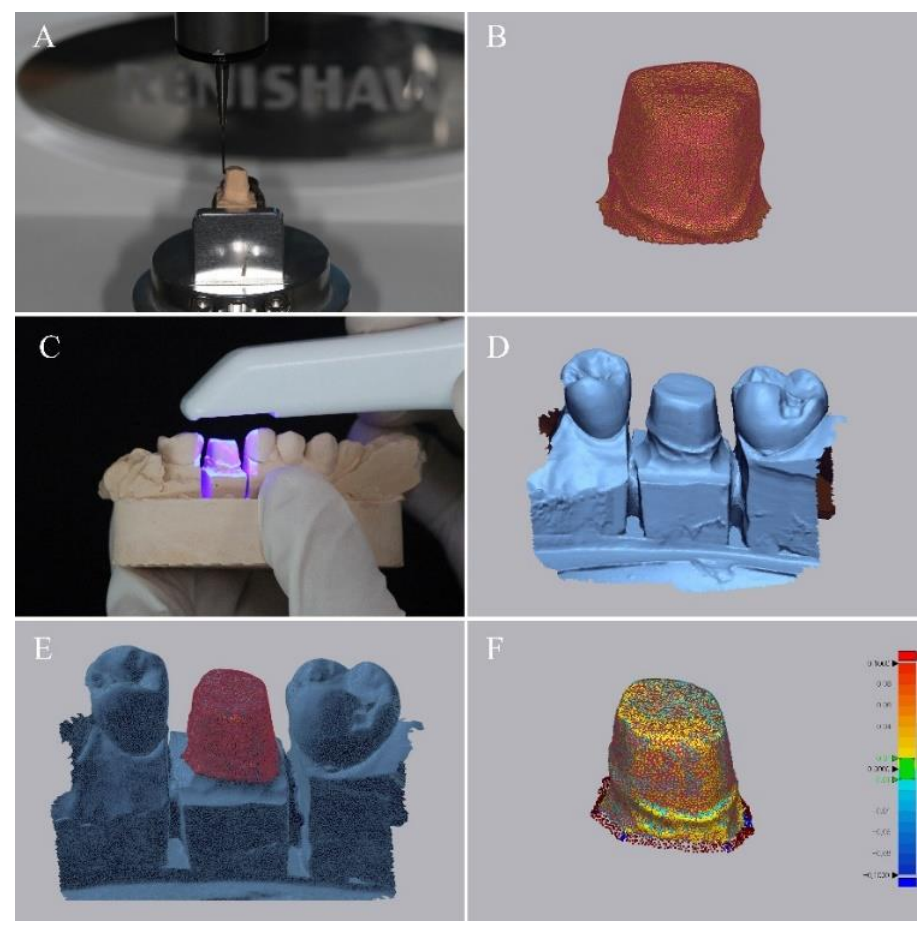

Figure 2. Procedure for evaluating $3 \mathrm{D}$ analysis. (A) Contact scanning procedure for CAD reference model (CRM). (B) CRM. (C) Scanning procedure for CAD test model (CTM). (D) CTM. (E) Superimposition of CRM and CTM. (F) 3D evaluation.

Three types of intraoral scanner (Figure 3), including CS3600 (Carestream Dental, Atlanta, GA, USA), i500 (MEDIT, Seoul, Korea), and EZIS PO (DDS, Seoul, Korea), and one 
laboratory scanner, E1 (3Shape A/S, Copenhagen, Denmark), were employed ( $n=15$ per scanner) (Figure 2). First, the abutments were precisely scanned, and the adjacent teeth were scanned. Furthermore, for 3D analysis, they were extracted in a stereolithography file format and used as the CTM.

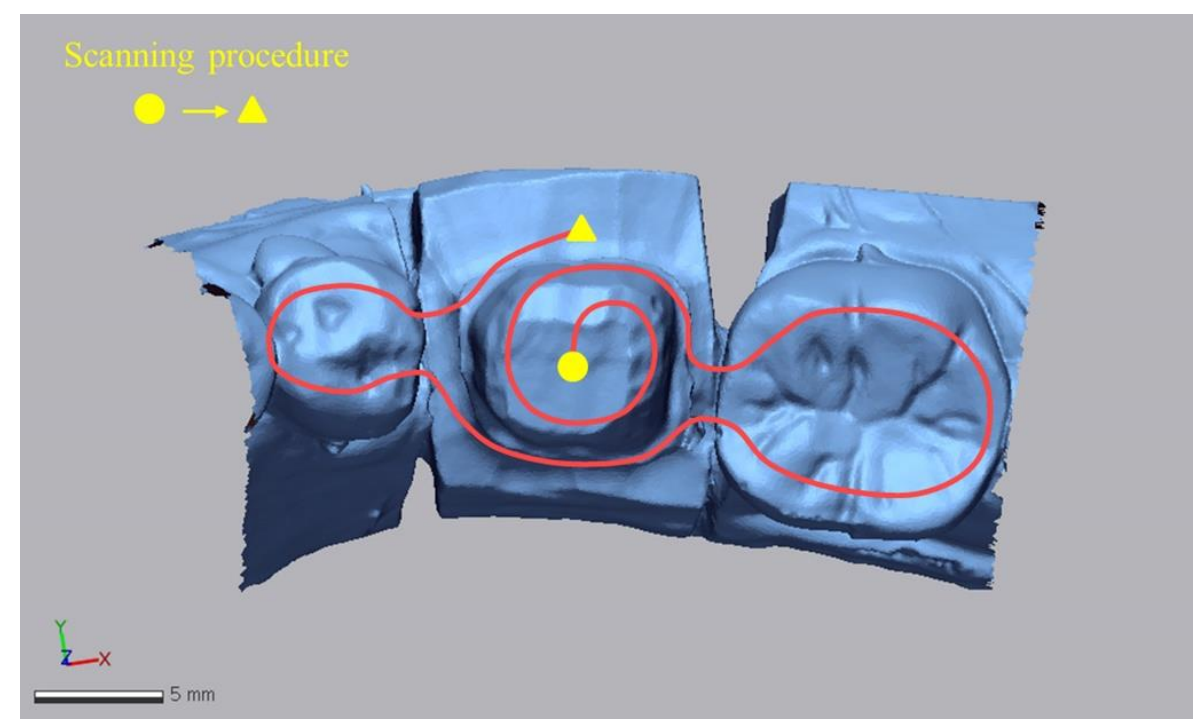

Figure 3. Scanning strategy for intraoral scanner.

The scanning accuracy analysis was performed using a 3D analysis software program (Geomagic control X; ver.2018.0.0, 3D Systems, Rock Hill, SC, USA). Based on the CRM, the CTM was superimposed (Figure 2). Optimal alignment was conducted by the following process: initial and best fit alignment. The sampling ratio was set to $100 \%$, based on the CRM. According to the algorithm of the 3D analysis software program (Geomagic control $\mathrm{X}$; ver.2018.0.0, 3D Systems, Rock Hill, SC, USA), the closest point-to-point among each point cloud of the CRM and the CTM was selected as the corresponding pairs. In addition, based on the results of the pilot experiment in the present study $(22.2 \pm 8.9 \mu \mathrm{m})$, the distance limit of the pairs selected in the software program was set to $50 \mu \mathrm{m}$, and pairs exceeding the distance limit were considered as incorrect corresponding pairs and excluded from the calculation. The dimensional differences between the CRM and the CTM were calculated for all data point clouds of the CRM. Next, the data points were calculated using the RMS value, using the following formula:

$$
R M S=\frac{1}{\sqrt{n}} \cdot \sqrt{\sum_{i=1}^{n}\left(X_{1, i}-X_{2, i}\right)^{2}}
$$

where, $X_{1, i}$ is the measurement point of $i$ of the CRM, and $X_{2, i}$ is the measurement point of $i$ of the CTM. In addition, $n$ refers to the number of all points measured in each analysis. The RMS value shows how much the deviation between the two different sets of data differs from 0 . Thus, a low RMS value represents a high degree of three-dimensional agreement of the overlapped data [19].

All the data were analyzed using SPSS statistical software (release 25.0, IBM, Chicago, IL, USA). The normal distribution of the data was investigated with the Shapiro-Wilk test. Using one-way and two-way ANOVA, the statistical significance was tested and the difference between the groups was tested using the Tukey HSD test as a post-test $(\alpha=0.05)$.

To analyze the correlations of the volume and area of the 10 abutments with the accuracy of the four types of scanners, Pearson's correlation analysis was conducted $(\alpha=0.00625$ with the Bonferroni correction method). The correlations were divided according to the Pearson's correlation coefficient (PCC) [37]. The correlations among the variables were expressed through perfect correlations ( $\mathrm{PCC}=+1$ or -1 ), strong correlations 
$(\mathrm{PCC}=+0.7$ to +0.9 or -0.7 to -0.9$)$, moderate correlations $(\mathrm{PCC}=+0.4$ to +0.6 or -0.4 to -0.6 ), and weak correlations ( $\mathrm{PCC}=+0.1$ to +0.3 or -0.1 to -0.3 ).

\section{Results}

There were significant differences between the scanning accuracies of the four types of scanner ( $p<0.001$; Figure 4; Table 1). The laboratory scanner (E1) demonstrated a high degree of accuracy, as did the CS3600 (Table 1). There was no significant difference between the i500 and EZIS PO scanners in terms of accuracy $(p>0.05$; Table 1$)$.

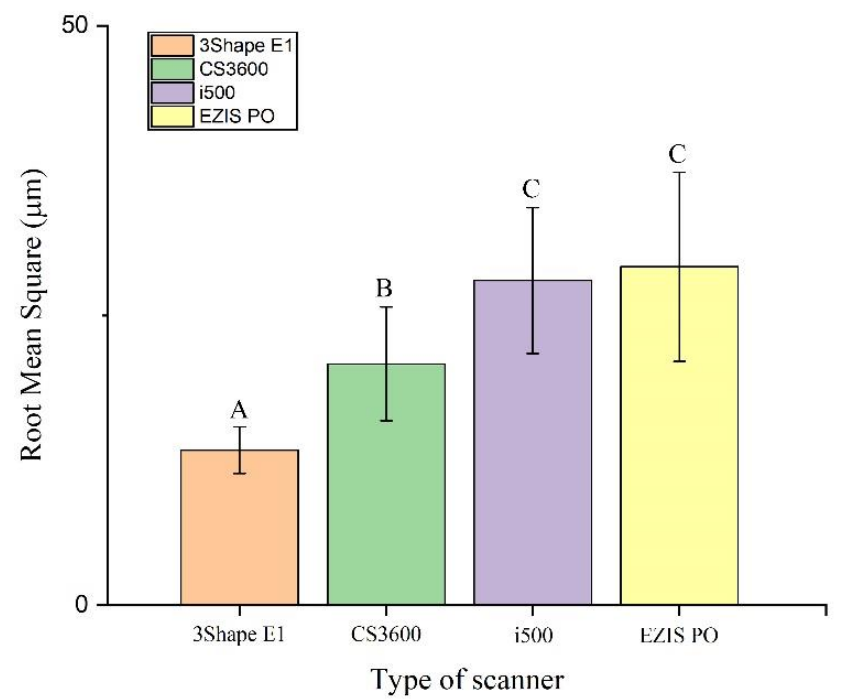

Figure 4. Comparison of RMS value according to scanner. Different letters $(A, B, C)$ indicate significant differences in the scanner group in the Tukey honestly significant difference test $(p<0.05)$.

Table 1. Comparison of RMS values per abutment type using 4 scanners.

\begin{tabular}{|c|c|c|c|c|}
\hline \multirow{2}{*}{ Scanner type } & Premolar & Molar & \multirow{2}{*}{$\mathbf{t}$} & \multirow{2}{*}{$p$} \\
\hline & \multicolumn{2}{|c|}{ Accuracy (Mean $\pm S D, \mu \mathrm{m})$} & & \\
\hline E1 & $12.8 \pm 2.0^{\mathrm{A}}$ & $13.8 \pm 1.1^{\mathrm{A}}$ & -3.964 & $<0.001$ * \\
\hline CS3600 & $17.5 \pm 3.6^{\mathrm{B}}$ & $24.0 \pm 3.7^{\mathrm{B}}$ & -10.963 & $<0.001$ * \\
\hline i500 & $23.4 \pm 3.9^{C}$ & $32.6 \pm 4.6^{C}$ & -9.333 & $<0.001$ * \\
\hline EZIS PO & $24.2 \pm 6.2^{C}$ & $34.1 \pm 6.7^{C}$ & -13.08 & $<0.001$ * \\
\hline $\mathbf{F}$ & 119.3 & 319.8 & & \\
\hline$p$ & $<0.001^{* *}$ & $<0.001^{* *}$ & & \\
\hline
\end{tabular}
indicate significant differences in the scanner group by the Tukey honestly significant difference test $(p<0.05)$.

There were significant differences between the accuracies for the premolars and molars in the four types of scanner; indeed, there was a high level of accuracy in the scanning of premolars $(p<0.001$; Figure 5; Table 1$)$. Furthermore, there was an interaction effect between the type of scanner and the type of tooth $(p<0.001$; Table 2$)$.

Table 2. Results from ANOVA for scanner type and tooth type.

\begin{tabular}{ccc}
\hline Scheme & F & $p$ \\
\hline Scanner type & 419.8 & $<0.001^{*}$ \\
\hline Tooth type & 348.3 & $<0.001^{*}$ \\
\hline Scanner type * Tooth type & 31.5 & $<0.001^{* *}$ \\
\hline
\end{tabular}

Significance determined by * one-way ANOVA and ${ }^{* *}$ two-way ANOVA, $p<0.05$. 


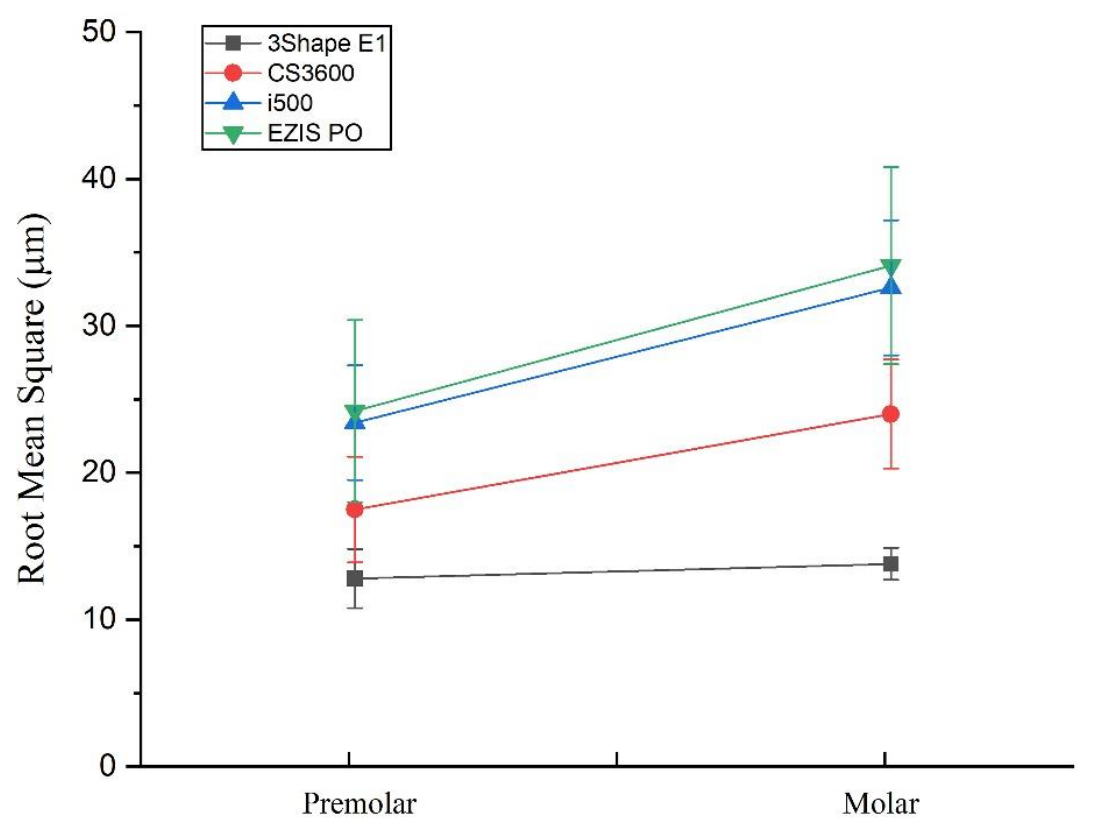

Figure 5. Comparison of RMS values for premolars and molars according to scanner.

The volume and area of 10 abutments and the accuracy of the four types of scanner showed significant positive correlations $(p<0.001$; Table 3$)$. There were weak correlations between the accuracy of the laboratory scanner (E1) and the volume (PCC =0.300) and area $(\mathrm{PCC}=0.349)(p<0.001$; Table 3$)$. There were moderate correlations between the accuracy of the CS3600 and the volume $(\mathrm{PCC}=0.625)$ and area $(\mathrm{PCC}=0.631)(p<0.001$; Table 3). There were strong correlations between the accuracy of the i500 and the volume $(\mathrm{PCC}=0.717)$ and area $(\mathrm{PCC}=0.725)(p<0.001$; Table 3$)$. There were strong correlations between the accuracy of the EZIS PO and the volume $(\mathrm{PCC}=0.743)$ and area $(\mathrm{PCC}=0.742)$ $(p<0.001$; Table 3).

Table 3. Correlation coefficient values for volume, area, and accuracy.

\begin{tabular}{cccccc}
\hline & & E1 & CS3600 & i500 & EZIS PO \\
\hline \multirow{2}{*}{ Volume } & PCC & 0.300 & 0.625 & 0.717 & 0.743 \\
\cline { 2 - 5 } & $p$ & $<0.001^{*}$ & $<0.001^{*}$ & $<0.001^{*}$ & $<0.001^{*}$ \\
\hline \multirow{2}{*}{ Area } & PCC & 0.349 & 0.631 & 0.725 & 0.742 \\
\cline { 2 - 5 } & $p$ & $<0.001^{*}$ & $<0.001^{*}$ & $<0.001^{*}$ & $<0.001^{*}$ \\
\hline
\end{tabular}

* Significance determined by Pearson correlation analysis, $p<0.00625$, with the Bonferroni correction method. PCC, Pearson correlation coefficient.

\section{Discussion}

The present study analyzed the accuracy of two types of abutments (premolar and molar), using three types of intraoral scanners (CS3600, i500, and EZIS PO) and one type of laboratory scanner (3shape E1), and analyzed the impacts of the volume and area of the abutments on the scanning accuracy. Between the four types of scanners, there were significant differences in the accuracy between premolars and molars, and the accuracy was excellent for premolars $(p<0.001$; Table 1$)$. In addition, there were significant positive correlations between the volume and area of the abutments and the accuracy of the four types of scanner $(p<0.001$; Table 3$)$. Therefore, all the null hypotheses of the present study were dismissed $(p<0.001)$. Lee et al. evaluated the scanning accuracy of an abutment for a single crown using two types of intraoral scanner (CEREC Bluecam and CEREC Omnicam) and reported a scanning accuracy similar to the results of the present study $(17.5 \pm 1.8 \mu \mathrm{m})$ (Table 1) [32]. Several studies that evaluated the scanning accuracy of an abutment for a single crown showed different positions and shapes of the abutment 
and did not present the volume and area. In addition, no previous research has been conducted on the impacts of the volume and area of abutments on the scanning accuracy. The results of the present study suggest that the volume and area of the abutments had significant positive correlations with the scanning accuracy $(p<0.001$; Table 3$)$. In an actual clinical environment, the preparation of various abutments is performed to produce a single crown [33], and on the basis of the results of the present study, it can be inferred that the greater the volume and area of an abutment, the poorer the scanning accuracy.

There were significant differences between the accuracies of the three types of intraoral scanner and one type of laboratory scanner used in the present study. The accuracy was highest with the laboratory scanner, and in the intraoral scanner group, the accuracy was highest with the CS3600. Previous studies have noted that if the scanning accuracy of virtual casts exceeds $100 \mu \mathrm{m}$, the fixed prostheses might fit incorrectly, and an acceptable range of scanning accuracy of less than $100 \mu \mathrm{m}$ has been proposed, based on the acceptable cement space of the fixed prostheses [24-26]. Thus, there were significant differences between the scanners used in the present study; however, all four types of scanner lay in the acceptable range of a scanning accuracy of less than $100 \mu \mathrm{m}$.

Kim et al. compared the scanning accuracy of nine types of intraoral scanners and reported significant differences depending on the scanners' image acquisition method [34]. The intraoral scanners used in the present study can be divided into a scanner using the individual image acquisition method (EZIS PO) and scanners using a video sequence acquisition method (CS3600 and i500). Previous studies reported that the individual image acquisition method took more scan time compared to the video sequence acquisition method and had a tendency toward poor scanning accuracy [35,36]. For this reason, most of the intraoral scanners recently released employ video sequence acquisition. In the present study, there were significant positive correlations between the volume and area of the abutments and the accuracy of the four types of scanner $(p<0.001$; Table 3$)$; however, there were differences in the correlations between the four types of scanner. The EZIS PO, which used the individual image acquisition method, showed the highest positive correlation, and such a strong correlation means that the impact on the scanning accuracy increases as the volume and area of the abutments increase. By contrast, the CS3600, which used the video sequence acquisition method, showed a moderate correlation, lower than that of the EZIS PO. The laboratory scanner showed weaker correlations compared to the group of intraoral scanners, which means that the impact on the scanning accuracy decreases as the volume and area of the abutments increase. As the intraoral scanner develops the entire video by continuously shooting the area in a small range, it has been reported that the greater the scanning range, the greater the error in the accuracy [27-29].

Many previous studies analyzed the accuracy of intraoral scanners in the completearch area [12-15]. Kang et al. analyzed the accuracy of five types of intraoral scanner in the complete-arch area and reported that the accuracy was worse in the posterior region than in the anterior region [36]. The present study evaluated the accuracy of a single abutment for a ceramic single crown and concluded that the RMS value was higher in the molar abutment than in the premolar abutment. Therefore, when using an intraoral scanner, the abutment should be selected considering the differences between intraoral scanners according to clinical conditions. In a study by Lee et al. [32], a single abutment with a general shape was scanned using an intraoral scanner and reported clinically acceptable accuracy. However, Park et al. reported that more complex and diverse abutment preparations in the dental clinical environment could affect the accuracy of intraoral scanners [33]. Therefore, the results of the present study can be used as data for the development of better intraoral scanners.

The present study has some limitations. First, the research was conducted in an in vitro environment, which did not reflect the possible conditions in the oral cavity (a wet environment and limited space). Previous studies have noted that these oral conditions could affect the accuracy of the scanner [12-15]. Thus, it is necessary to conduct an additional study to evaluate accuracy that considers the possible conditions in the oral 
cavity. In addition, the present study evaluated accuracy, using premolar and molar abutments; however, it is necessary to verify the analysis of the accuracy of the scanning of a more diverse range of abutment teeth through an additional study, including the anterior teeth. Finally, to obtain more significant results than in the present study, additional studies should be conducted to increase the number of samples.

\title{
5. Conclusions
}

Given the limitations of this in vitro study, the following conclusions were drawn.

1. Scanning accuracy may be affected by the types of abutment (premolar and molar) and scanner; however, all the scanners used in the present study showed a clinically acceptable scanning accuracy $(<100 \mu \mathrm{m})$.

2. The volume and area of the abutments showed a positive correlation with the scanning accuracy. The correlations were highest with the intraoral scanner (EZIS PO), while the correlations were weak with the laboratory scanner (E1). Thus, the greater the volume and area of the scanned abutment, the worse the scanning accuracy becomes.

3. Therefore, clinicians should choose scanners according to the clinical situation.

\begin{abstract}
Author Contributions: Conceptualization, D.-G.L. and K.S.; methodology, K.S.; validation, K.-b.L.; formal analysis, D.-G.L. and K.S.; investigation, D.-G.L.; data curation, K.-b.L.; writing-original draft, D.-G.L. and K.S.; writing-review and editing, D.-G.L. and K.S.; statistical analysis, K.S.; visualization, K.S.; supervision, K.-b.L.; project administration, K.-b.L. All authors have read and agreed to the published version of the manuscript.
\end{abstract}

Funding: This work was supported by the Industrial Strategic Technology Development Program (10062635, New hybrid milling machine with a resolution of less than $10 \mu \mathrm{m}$ development, using open CAD/CAM S/W integrated platforms for one-day prosthetic treatment of 3D smart medical care system), funded by the Ministry of Trade, Industry and Energy (MOTIE, Korea). This work was also supported by Industrial Infrastructure Program of Laser Industry Support (Grant N0000598) funded by the Ministry of Trade, Industry and Energy (MOTIE, Korea).

Institutional Review Board Statement: Not applicable.

Informed Consent Statement: Not applicable.

Data Availability Statement: Data are included within the article.

Acknowledgments: The authors would like to thank the researchers of the Advanced Dental Device Development Institute, Kyungpook National University, for their time and contributions to the study.

Conflicts of Interest: The authors declare no conflict of interest. The funders had no role in the design of the study, in the collection, analysis, or interpretation of the data, in the writing of the manuscript, or in the decision to publish the results.

\section{References}

1. Su, Y.; Xin, M.; Chen, X.; Xing, W. Effect of CAD-CAM ceramic materials on the color match of veneer restorations. J. Prosthet. Dent. 2021, 126, 255.e1-255.e7. [CrossRef] [PubMed]

2. Çakmak, G.; Yilmaz, H.; Aydoğ, Ö.; Yilmaz, B. Flexural strength of CAD-CAM and conventional interim resin materials with a surface sealant. J. Prosthet. Dent. 2020, 124, 800.e1-800.e7. [CrossRef] [PubMed]

3. Rayyan, M.M.; Aboushelib, M.; Sayed, N.M.; Ibrahim, A.; Jimbo, R. Comparison of interim restorations fabricated by CAD/CAM with those fabricated manually. J. Prosthet. Dent. 2015, 114, 414-419. [CrossRef] [PubMed]

4. Zarone, F.; Ruggiero, G.; Ferrari, M.; Mangano, F.; Joda, T.; Sorrentino, R. Accuracy of a chairside intraoral scanner compared with a laboratory scanner for the completely edentulous maxilla: An in-vitro 3-dimensional comparative analysis. J. Prosthet. Dent. 2020, 124, 761.e1-761.e7. [CrossRef] [PubMed]

5. Lim, J.H.; Park, J.M.; Kim, M.; Heo, S.J.; Myung, J.Y. Comparison of digital intraoral scanner reproducibility and image trueness considering repetitive experience. J. Prosthet. Dent. 2018, 119, 225-232. [CrossRef] [PubMed]

6. Kim, J.E.; Amelya, A.; Shin, Y.; Shim, J.S. Accuracy of intraoral digital impressions using an artificial landmark. J. Prosthet. Dent. 2017, 117, 755-761. [CrossRef]

7. Mejía, J.B.C.; Wakabayashi, K.; Nakamura, T.; Yatani, H. Influence of abutment tooth geometry on the accuracy of conventional and digital methods of obtaining dental impressions. J. Prosthet. Dent. 2017, 118, 392-399. [CrossRef] [PubMed] 
8. Murat, S.; Batak, B. Fabrication of a 3-dimensionally printed definitive cast for an obturator prosthesis by merging intraoral scan image with cone beam computed tomography data: A clinical report. J. Prosthet. Dent. 2021, 126, 256.e1-256.e4. [CrossRef]

9. Sakornwimon, N.; Leevailoj, C. Clinical marginal fit of zirconia crowns and patients' preferences for impression techniques using intraoral digital scanner versus polyvinyl siloxane material. J. Prosthet. Dent. 2017, 118, 386-391. [CrossRef]

10. Marchand, L.; Touati, R.; Fehmer, V.; Ducret, M.; Sailer, I. Latest advances in augmented reality technology and its integration into the digital workflow. Int. J. Comput. Dent. 2020, 23, 397-408.

11. Liu, C.; Guo, J.; Gao, J.; Yu, H. Computer-assisted tooth preparation template and predesigned restoration: A digital workflow. Int. J. Comput. Dent. 2020, 23, 351-362.

12. Wong, K.Y.; Esguerra, R.J.; Chia, V.A.P.; Tan, Y.H.; Tan, K.B.C. Three-dimensional accuracy of digital static interocclusal registration by three intraoral scanner systems. J. Prosthodont. 2018, 27, 120-128. [CrossRef]

13. Revilla-León, M.; Subramanian, S.G.; Att, W.; Krishnamurthy, V.R. Analysis of different illuminance of the room lighting condition on the accuracy (trueness and precision) of an intraoral scanner. J. Prosthodont. 2021, 30, 157-162. [CrossRef]

14. Flügge, T.V.; Att, W.; Metzger, M.C.; Nelson, K. Precision of dental implant digitization using intraoral scanners. Intern J. Prosthodont. 2016, 29, 277-283. [CrossRef]

15. Motel, C.; Kirchner, E.; Adler, W.; Wichmann, M.; Matta, R.E. Impact of different scan bodies and scan strategies on the accuracy of digital implant impressions assessed with an intraoral scanner: An in-vitro study. J. Prosthodont. 2020, 29, 309-314. [CrossRef]

16. Oh, K.C.; Lee, B.; Park, Y.B.; Moon, H.S. Accuracy of three digitization methods for the dental arch with various tooth preparation designs: An in-vitro study. J. Prosthodont. 2019, 28, 195-201. [CrossRef]

17. Kim, J.E.; Hong, Y.S.; Kang, Y.J.; Kim, J.H.; Shim, J.S. Accuracy of scanned stock abutments using different intraoral scanners: An in-vitro study. J. Prosthodont. 2019, 28, 797-803. [CrossRef]

18. Ammoun, R.; Suprono, M.S.; Goodacre, C.J.; Oyoyo, U.; Carrico, C.K.; Kattadiyil, M.T. Influence of tooth preparation design and scan angulations on the accuracy of two intraoral digital scanners: An in-vitro study based on 3-dimensional comparisons. J. Prosthodont. 2020, 29, 201-206. [CrossRef] [PubMed]

19. Güth, J.F.; Runkel, C.; Beuer, F.; Stimmelmayr, M.; Edelhoff, D.; Keul, C. Accuracy of five intraoral scanners compared to indirect digitalization. Clin. Oral Investig. 2017, 21, 1445-1455. [CrossRef] [PubMed]

20. Ashraf, Y.; Sabet, A.; Hamdy, A.; Ebeid, K. Influence of preparation type and tooth geometry on the accuracy of different intraoral scanners. J. Prosthodont. 2020, 29, 800-804. [CrossRef] [PubMed]

21. Chiu, A.; Chen, Y.W.; Hayashi, J.; Sadr, A. Accuracy of CAD/CAM digital impressions with different intraoral scanner parameters. Sensors 2020, 20, 1157. [CrossRef]

22. Patzelt, S.B.; Emmanouilidi, A.; Stampf, S.; Strub, J.R.; Att, W. Accuracy of full-arch scans using intraoral scanners. Clin. Oral Investig. 2014, 18, 1687-1694. [CrossRef]

23. Son, K.; Lee, W.S.; Lee, K.B. Prediction of the learning curves of 2 dental CAD software programs. J. Prosthet. Dent. 2019, 121, 95-100. [CrossRef]

24. Park, G.H.; Son, K.; Lee, K.B. Feasibility of using an intraoral scanner for a complete-arch digital scan. J. Prosthet. Dent. 2019, 121, 803-810. [CrossRef]

25. Ender, A.; Attin, T.; Mehl, A. In vivo precision of conventional and digital methods of obtaining complete-arch dental impressions. J. Prosthet. Dent. 2016, 115, 313-320. [CrossRef]

26. Fukazawa, S.; Odaira, C.; Kondo, H. Investigation of accuracy and reproducibility of abutment position by intraoral scanners. J. Prosthodont. Res. 2017, 61, 450-459. [CrossRef] [PubMed]

27. Son, K.; Jin, M.U.; Lee, K.B. Feasibility of using an intraoral scanner for a complete-arch digital scan, part 2: A comparison of scan strategies. J. Prosthet. Dent. 2021, in press. [CrossRef]

28. Zhang, Y.J.; Shi, J.Y.; Qian, S.J.; Qiao, S.C.; Lai, H.C. Accuracy of full-arch digital implant impressions taken using intraoral scanners and related variables: A systematic review. Int. J. Oral Implantol. 2021, 14, 157-179.

29. Rutkūnas, V.; Gečiauskaitè, A.; Jegelevičius, D.; Vaitiekūnas, M. Accuracy of digital implant impressions with intraoral scanners. A systematic review. Eur. J. Oral Implantol. 2017, 10, 101-120.

30. Huang, M.Y.; Son, K.; Lee, K.B. Effect of distance between the abutment and the adjacent teeth on intraoral scanning: An in-vitro study. J. Prosthet. Dent. 2021, 125, 911-917. [CrossRef] [PubMed]

31. Son, K.; Lee, K.B. Effect of finish line locations of tooth preparation on the accuracy of intraoral scanners. Int. J. Comput. Dent. 2021, 24, 29-40.

32. Lee, J.J.; Jeong, I.D.; Park, J.Y.; Jeon, J.H.; Kim, J.H.; Kim, W.C. Accuracy of single-abutment digital cast obtained using intraoral and cast scanners. J. Prosthet. Dent. 2017, 117, 253-259. [CrossRef]

33. Park, J.M.; Kim, R.J.Y.; Lee, K.W. Comparative reproducibility analysis of 6 intraoral scanners used on complex intracoronal preparations. J. Prosthet. Dent. 2020, 123, 113-120. [CrossRef] [PubMed]

34. Kim, R.J.Y.; Park, J.M.; Shim, J.S. Accuracy of 9 intraoral scanners for complete-arch image acquisition: A qualitative and quantitative evaluation. J. Prosthet. Dent. 2018, 120, 895-903. [CrossRef] [PubMed]

35. Son, K.; Lee, K.B. Effect of tooth types on the accuracy of dental 3d scanners: An in-vitro study. Materials 2020, 13, 1744. [CrossRef] [PubMed] 
36. Kang, B.H.; Son, K.; Lee, K.B. Accuracy of five intraoral scanners and two laboratory scanners for a complete arch: A comparative in-vitro study. Appl. Sci. 2020, 10, 74. [CrossRef]

37. Son, K.; Lee, K.B. Effect of computer literacy on the working time of the dental CAD software program. J. Prosthodont. Res. 2021, 65, 255-260. [CrossRef] 